\title{
Non-conventional approach in single-sided lapping process: kinematic analysis and parameters optimization
}

\author{
Adam Barylski ${ }^{1} \cdot$ Norbert Piotrowski $^{1}$ \\ Received: 15 November 2017 / Accepted: 26 August 2018 / Published online: 27 September 2018 \\ (C) The Author(s) 2018
}

\begin{abstract}
The lapping process is strongly affected by a number of input parameters. One of the fundamental mechanical processes in lapping is the abrasive effect of particles. In order to examine the influence of the kinematic parameters on the lapping uniformity of unconventional single-sided machine, numerical simulations of particles sliding trajectories are performed. Changing the kinematic parameters, e.g., rotational velocities or position of the conditioning rings together with the workpieces can be used for correcting the profile of an active surface of the lap. This paper provides a basic guide to the kinematic parameter settings of single-sided lapping process. Furthermore, an unconventional single-sided lapping system, where a conditioning ring performs additional motion during the machining, is described. Simulation results show that the rotational speed ratio of the conditioning ring to the lapping plate $k_{1}$ and the period ratio of the reciprocating motion to the lapping plate rotary motion $k_{2}$ represent the relationships among the three basic motions of unconventional lapping systems and are major factors affecting trajectory distribution. Material removal rate and trajectory density parameter are proposed to optimize the kinematic parameters for better uniformity of lapping plate wear. The preferred kinematic parameter values for single-sided lapping system with reciprocating motions and the assumed size of the machine are $k_{1}=0,78$ and $k_{2}=2$. The general results were validated on a specially designed test stand.
\end{abstract}

Keywords Abrasive machining $\cdot$ Single-sided lapping $\cdot$ Particle trajectory $\cdot$ Kinematic optimization

\section{Introduction}

In order to achieve high-quality surfaces with low roughness, very high accuracy of shape and dimensions, finishing technologies become more important and are nowadays state of the art. Grinding, lapping, polishing and chemicalmechanical polishing (CMP) are all techniques used for precise removal of material. One of the most effective planarization technology among the most widely used is single-sided lapping process, which has become a major finishing technology in manufacturing many parts, e.g., valve plates or ceramic sealing rings [1]. However, the process can be applied also in different materials: metals and their alloys [2]; glasses [3]; natural materials like marble, granite, or basalt; and materials used in semiconductor technology

Norbert Piotrowski

norbert.piotrowski@pg.edu.pl

1 Gdansk University of Technology, ul. Gabriela Narutowicza 11/12, 80-233 Gdansk, Poland
$[4,5]$, as well as carbon, graphite, and even diamond [6]. During lapping process, loose abrasive grains are provided between two surfaces and relative motions between them result in a finish of multi-directional lay [7]. However, to ensure the highest quality and accuracy on worked surfaces, it is crucial to improve conventional lapping techniques or to develop new working principles. Therefore, research should focus on improving the lapping process by studying significant process variables.

The single-sided lapping process is affected by numerous technologically based conditions, which have an influence on the tool wear, workpiece quality, and efficiency of the process. An overview of this relationship is presented in Fig. 1. Generally, it can be stated that during a single-sided lapping process, a tool, type of abrasives and workpieces, kinematics, and machine parameters decisively affect the mechanism of surface formation [8]. Moreover, the studies have shown that with increasing diameter of lapping grains, the material removal rate increases [9]. Of great significance is also the type of grain material and carrier fluid, as well as concentration and volume of abrasive slurry [10]. 


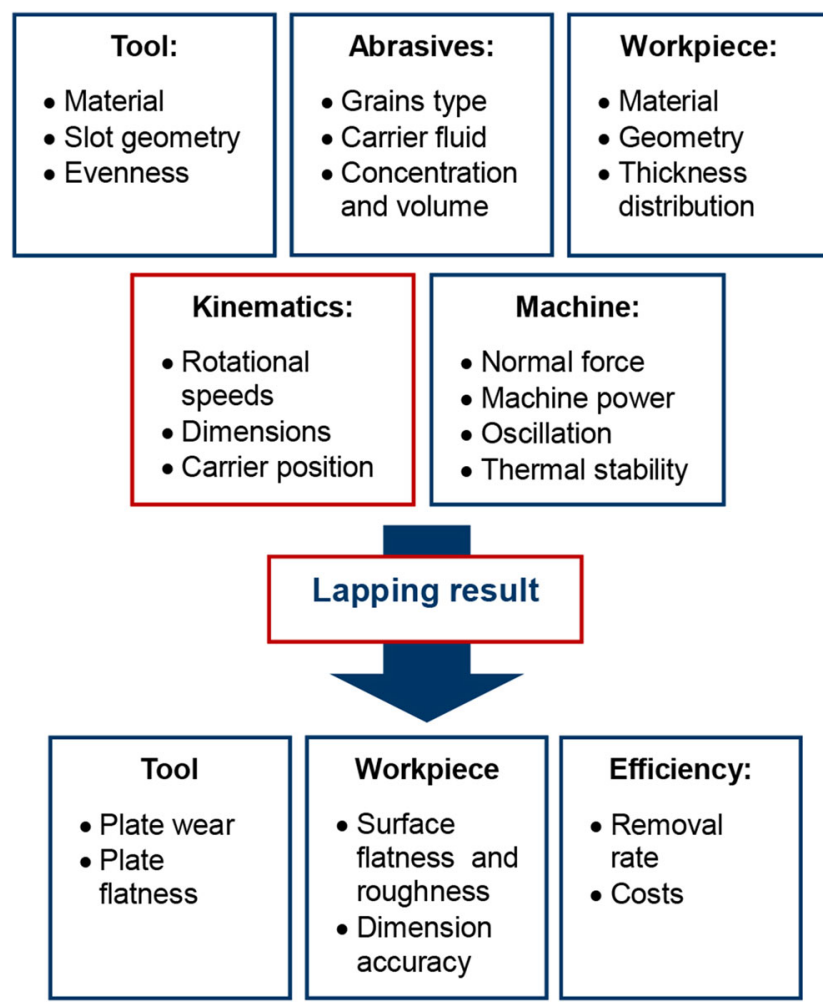

Fig. 1 Input and output parameters in lapping process

In addition, the lapping efficiency are influenced by the geometry and material of workpieces [11].

The lapping result depends on the proper control of lapping parameters such as lapping pressure and speed rotation of the lapping plate and conditioning rings [12]. They are closely interrelated with the kinematic system and machine parameters and cannot be adjusted directly in the lapping process. Moreover, a significant influence over a dimensional and profile accuracy, as well as over a surface quality of a workpiece has the lapping plate. It could be established that workpieces are machined to a mirror image of the tool with respect to the flatness [13]. Since the wear of the lapping plate is not constant over the diameter, it does not remain flat and causes the following shape errors: convexity, concavity, and axial run-out. Hence, it is crucial to maintain proper conditions of the process, control the flatness and condition the tool, when it is necessary [14].

Previous researches on single-sided lapping kinematics have focused primarily on determining an influence of workpieces geometry, their distribution in conditioning rings [11], and analysis of abrasives path distribution [15]. Few researchers have addressed the problem of conditioning the tool after the lapping process [14]. Many studies have been published on material removal mechanisms. Ichikawa et al. [16] presented a lapping method and the relationship between lapping pressure, the wear-distance ratio, the mesh number of the abrasive sheet, and sphericity of balls. Chang et al. [17] investigated the mechanical material removal (MRR) mechanisms using concepts of two-body vs. threebody abrasion and ductile vs. brittle machining. Kling et al. [18] described the material removal mechanisms, lapping kinematics and material removal from the workpiece and lap wear in plane and plane-parallel lapping. In the researches of Spur, Eichhorn, and Simpfendörfer [19, 20], the workpiece in the single-sided lapping process was described by distances passing through points that are arranged along the radius of the conditioning ring. The sum of the distances at infinite number of points gives the effective surface of the workpiece. Then, the surface of the lapping plate was divided into rings and the total value of the distances on each ring was calculated to measure MRR. To obtain optimal parameters in single-sided lapping, $\mathrm{Hu}$, Fang, Deng et. al. [21] used a method of extracting abrasive position information. The work focuses on optimizing speed ratio of a fixed abrasive diamond pellet pad for lapping alumina ceramic based on trajectory analysis. However, most of researches provide information about a standard kinematic system of single-sided lapping machines and there has been little discussion on new kinematics systems.

Lapping kinematics was also analyzed in numerous studies on double-sided lapping systems [22, 23]. An important advantage of double-sided lapping is the possibility of achieving a small dimensional tolerance (thickness) and improved parallelism. Nonetheless, single-sided lapping, in addition to specified stereometric structure, provides a high flatness and straightness and has less limitations. Moreover, lapping processes can be substituted by face grinding on lapping machines [1, 24, 25], which offers a new field of application for the kinematic model of relative motions in lapping. The similar kinematics is also used in chemical-mechanical polishing (CMP), which is a complex mechanical and chemical process widely used in wafer planarization. In contrast to single-sided lapping systems, rotary-type CMP systems mainly consist of one wafer carrier and pad conditioner [26]. The conditioner is a mechanism that moves a hard abrading surface across pad surface to restore its planarity and roughness [27]. Several studies have been carried out on the effects of kinematic variables on the non-uniformity of the wafer. The effects of the rotational and translational speeds and carrier eccentricity were discussed by Hocheng et al. [28]. Lee [29] investigates the relationship between swing-arm conditioning and material removal rate (MRR) profile in CMP. In order to investigate the pad wear non-uniformity, an analytical model was established by Nguyen et al. [30]. Researchers, by combining of the kinematic motions and the contact time, indicated that the cutting path density and the contact time near the pad center are more than that near the pad edge.

This paper provides a basic guide to the kinematic parameter settings of the single-sided lapping process. 
Presented in this paper, the unconventional single-sided lapping system ensures the optimal constant wear over the diameter. In a new system, a conditioning ring performs an additional reciprocating motion during the machining. In the initial stage of research, kinematic equations were mathematically developed to describe the relationship between any position of a single abrasive on the lapping plate. Then, the lapping plate wear model was in detail described. The trajectories of single abrasive were simulated and their distribution on lapping plate was analyzed. The uniformity of tool wear was assumed as the main optimization criterion. Finally, an experimental stand has been described and a set of tests for different parameters were conducted.

\section{Single-sided lapping systems}

\subsection{Standard single-sided lapping system}

Many machine tools manufactured offer planarization technology on lapping machines or grinding machines with lapping kinematics. Most of them have the standard kinematic system (Fig. 2). Single-sided lapping machines are equipped with one annular-shaped plate (1) and usually have three to four conditioning rings (3). The lap rotates with angular velocity $\omega_{t}$ and drives conditioning rings, where separators (4) are placed, allowing additional move of workpieces (5). Conditioning rings are rotated with angular velocity $\omega_{s}$ by the frictional force. This force depends on a radial position, velocity of conditioning rings, and friction conditions. The radial position of conditioning rings $R_{p}$ can be controlled with roller forks (2). During machining, a certain load is provided through felt pad (6) by weight disk (7) or pneumatic system [3].

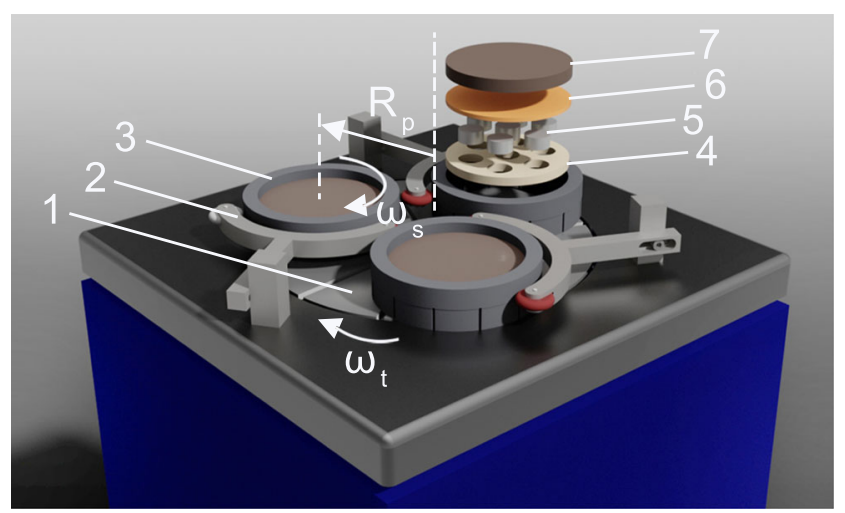

Fig. 2 Single-sided lapping machine: 1-lapping plate, 2-roller fork, 3 - conditioning ring, 4-separator, 5-workpieces, 6-felt pad, 7weight disk, $\omega_{t}$ angular velocity of lapping plate, $\omega_{s}$-angular velocity of conditioning ring, $R_{p}$-distance from the center of lapping plate to the center of conditioning ring

\subsection{Unconventional lapping systems}

It was claimed that the material removal in lapping is caused by the cutting action of embedded abrasive grains. Computer simulations have shown that changing the kinematic system of single-sided lapping process, by an introduction of an additional movement of the conditioning ring, changes the density of grains trajectories. Studied were the densities of trajectories in unconventional lapping systems, where the conditioning ring performs additional moves along the radius and chord or swings and moves off-center [31]. The considerations regarding complex kinematics of the lapping process were the starting point to develop automated lapping system [32]. The idea of how the single-sided lapping machine and the robot working together is presented in Fig. 3.

After numerous simulations and careful analysis, it was observed that the most crucial parameter is the distance between the center of the conditioning ring and the center of the lapping plate, which in studied systems changes a value during time [32]. The kinematics of single-sided lapping system with the additional movement of the conditioning ring along a chord is indicated in Fig. 4. In this idea, there is only one conditioning ring, which in addition to rotary motion, performs a reciprocating motion between point $A$ and $B$. The position of the conditioning ring $R_{p x}(t)$ changes the value in time and the distance from the center of the lapping plate to the chord equals $R_{p y}$.

The position of any point $S\left(r_{s}, \varphi_{s}\right)$ belonging to a workpiece in radial lapping system are determined in $x^{\prime \prime} y^{\prime \prime}$ coordinate system, which is related to conditioning ring as:

$x_{s}^{\prime \prime}=-r_{s} \cdot \cos \left(\varphi_{s}\right)$
$y_{s}^{\prime \prime}=-r_{s} \cdot \sin \left(\varphi_{s}\right)$

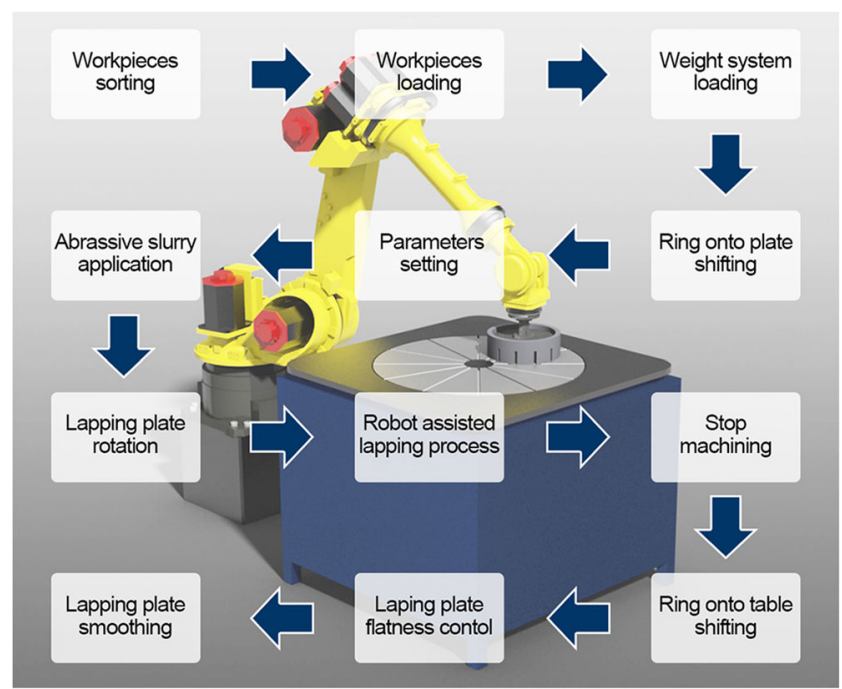

Fig. 3 Idea of robotic single-sided lapping system 


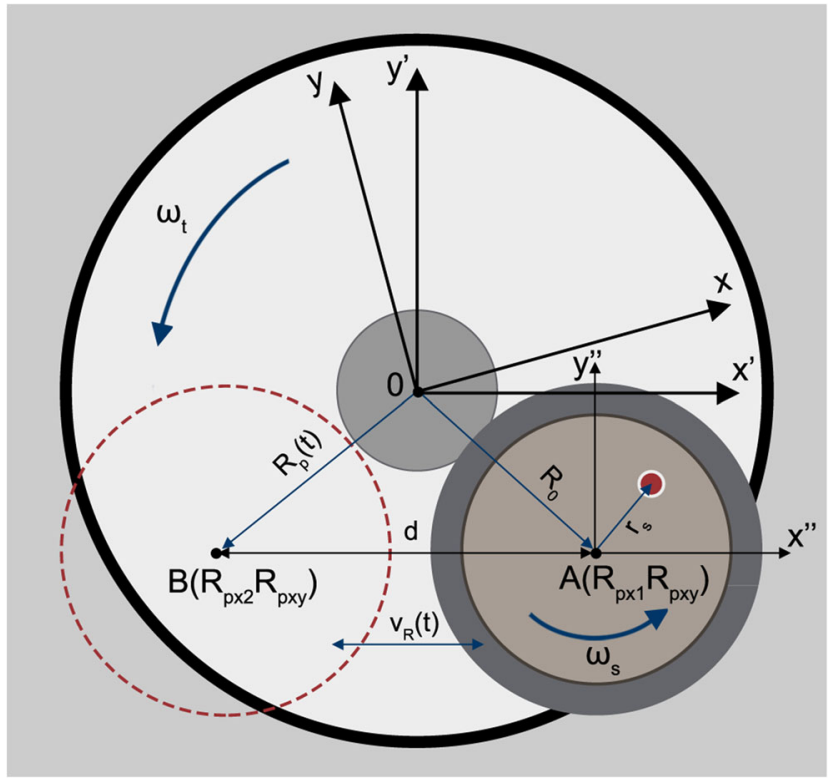

Fig. 4 Diagram of single-sided lapping machine with reciprocating movement of conditioning ring

The coordinates of point $S$ in $x^{\prime} y^{\prime}$ coordinate system are:

$x_{s}^{\prime}=x_{s}^{\prime \prime} \cdot \cos \left(\omega_{s} \cdot t\right)+y_{s}^{\prime \prime} \cdot \sin \left(\omega_{s} \cdot t\right)+R_{p x}(t)$

$y_{s}^{\prime}=-x_{s}^{\prime \prime} \cdot \sin \left(\omega_{s} \cdot t\right)+y_{s}^{\prime \prime} \cdot \cos \left(\omega_{s} \cdot t\right)+R_{p y}$

After transforming it to coordinate system related to rotating lapping plate:

$x_{s}=x_{s}^{\prime} \cdot \cos \left(\omega_{t} \cdot t\right)+y_{s}^{\prime} \cdot \sin \left(\omega_{t} \cdot t\right)$

$y_{s}^{\prime}=-x_{s}^{\prime} \cdot \sin \left(\omega_{t} \cdot t\right)+y_{s}^{\prime} \cdot \cos \left(\omega_{t} \cdot t\right)$

The relative velocity $v$ of point $S$ is defined as the derivative of the position with respect to time.

\section{Lapping plate wear model}

One of the commonly used method to predict the profile wear of the abrasive processes is the tribological model developed by Preston, who was studying the effects of grinding glass. The model that related relative velocity and pressure to material removal rate (MRR) is known as Preston's equation [33]:

$\frac{d H}{d t}=k \cdot p \cdot v$

In single-sided lapping, polishing or grinding Preston's coefficient $k$ and force per unit area $p$ are constant in time [34]. The value change only the relative velocity of lapping $v$, which can be calculated from the kinematic equations.

Most of already developed models of the lapping plate wear assume that the wear intensity depends on a contact intensity of the tool with the workpieces through the lapping abrasive grains [35]. One way to determine the contact intensity is calculating a particles density of interpolated trajectories. A Matlab program was designed to simulate the trajectories and to count their distribution. It can be predicted that during the lapping process, there can be more than one million active particles. However, because of the calculation time, an appropriate particle number, which can reflect the same regularity as the real number, has to be determined. Fig. 5 gives an example of the calculation steps for the case of five random particles. First, the particle locations are generated within the conditioning ring using a random function (Fig. 5a). Then, the trajectories of the particles are calculated using the kinematic equations (Fig. 5b-c). Interpolation function is used to calculate a set of points, which are equally spaced from each other (Fig. 5d). The lapping plate surface is divided into small squares with the same area. Finally, a statistics function is used to count the total number of points within each square of the lapping plate surface, and the path density a)

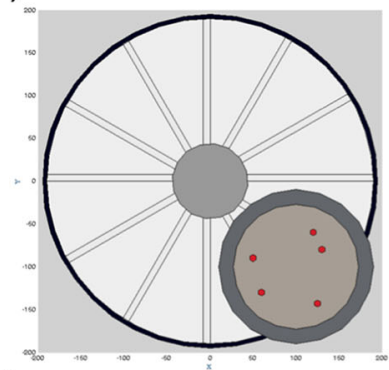

c)

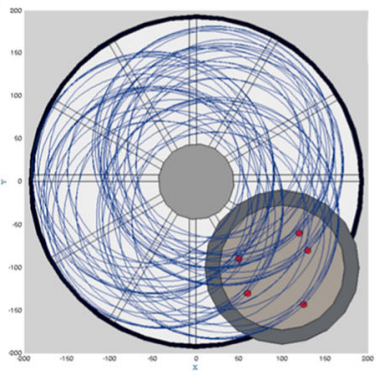

e)

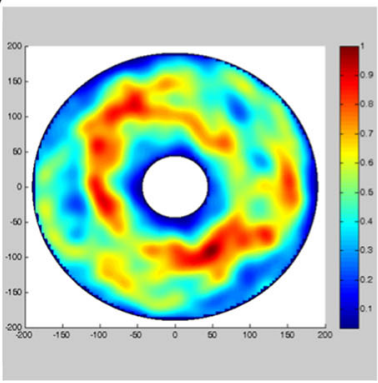

b)

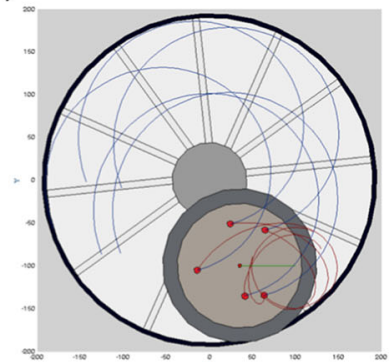

d)

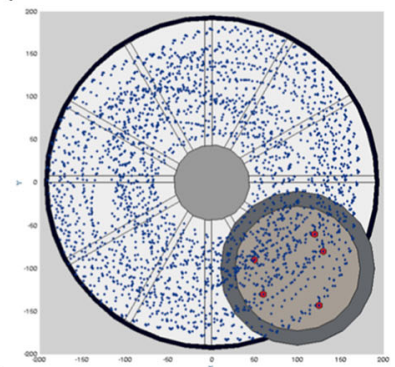

f)

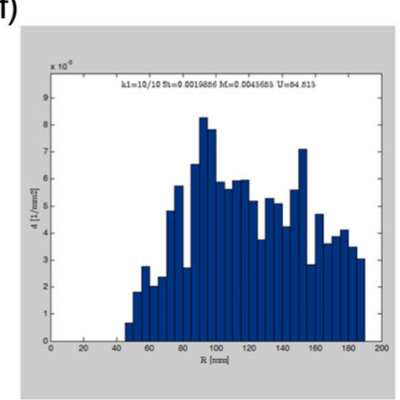

Fig. 5 Steps of trajectories density determination: a random generated particles b-c trajectories generating, d trajectories interpolation, e density of trajectories, $\mathbf{f}$ profile density of trajectories 
is calculated (Fig. 5e). In order to determine if the wear causes a concavity or the convexity, the contact intensity can be developed for a profile of the tool (Fig. 5f). It can be achieved by dividing the area of the lapping plate into equal rings. The density is a measure of the points in in an appropriate area and it is determined by equation:

$D_{i}=\frac{n_{i}}{A_{i}-A_{i-1}}=\frac{n_{i}}{(2 i-1) \pi r^{2}}$

where: $n$ is a points number in area $A_{i}$ and $r$ is the ring width. The equation of material removal speed by a single grain within the area of each ring, which takes into account the contact intensity and the velocity of any point on the lapping plate, can be simplified as:

$H_{i}=\frac{k p \sum v_{i}}{(2 i-1) \pi r^{2}}$

The standard deviation $S_{D}$ of all the values of $H_{i}$ is given by:

$S_{D}=\sqrt{\frac{\sum_{i}^{N}\left(H_{i}-\bar{H}\right)^{2}}{N-1}}, i=1,2,3 \ldots . N$

where $\bar{H}$ represents the average of all the values and $N$ is the total number of the divided rings or squares [36].

\section{Parameters optimization}

Kinematic analysis reveals that the basic kinematic parameters significantly affect the trajectory and velocity distributions. In order to get the best performance, rationally designing the rotation parameters of the lapping plate and workpiece is one of the key technological points.

For the simplicity, the velocity expressions, two nondimensional parameters, the rotational speed ratio of the conditioning ring to the lapping plate $k_{1}$, and period ratio of the reciprocating period to the lapping plate rotary motion period $k_{2}$ are defined by Eqs. 11 and 12:

$k_{1}=\frac{\omega_{s}}{\omega_{t}}$

$k_{2}=\frac{T_{R}}{T_{T}}=\frac{d}{v_{R}} \frac{\omega_{t}}{\pi}$

where $d$ is the reciprocating stroke and $T_{R}$ and $T_{T}$ are the periods of the reciprocating motion of the conditioning ring and rotary motion of the lapping plate. Considering the reciprocating motion of the conditioning ring, $R_{p}$ is a function of time and it can be expressed as:

$R_{p}=R_{0}+\Delta R$

where $R_{0}$ is original center distance between the lapping plate and the conditioning ring and $\Delta R$ is an integral of the velocity $v_{R}$.
In order to describe the particle trajectories more precisely, the translational motion of the conditioning ring should be further determined. It was observed that the conditioning ring should move on the entire lapping plate in such a way to ensure its even wear. However, there are many ways in position control applications to move from one point to another. The most common are trapezoidal and S-curve motions. In the trapezoidal move profile, velocity is changed linearly. The main disadvantage of this motion is that the acceleration makes abrupt changes [37]. It is quantified in an S-curve motion profile by "jerk" as the time derivative of acceleration. This can help to smooth the motion and reduce the possibility of exciting a vibration or oscillation [38]. As shown in Fig. 6, the conditioning ring moves between points $A$ and $B$; the distance between them is a reciprocating stroke and it equals $d . T_{R}$ is the reciprocating period, $T_{A}$ is the acceleration time of the uniformly accelerated motion, and $T_{D}$ is the deceleration time of the uniformly decelerated motion. It was assumed that the conditioning ring has a maximum velocity $v_{R \max }$ at the central range of the reciprocating stroke and uniformly accelerated and decelerated motions at the two ends of the stroke.

$T_{A}=T_{D}=\frac{d}{2 v_{\text {Rmax }}}$

$J_{A}=-J_{D}=\frac{v_{R \max }}{T_{A}^{2}}$
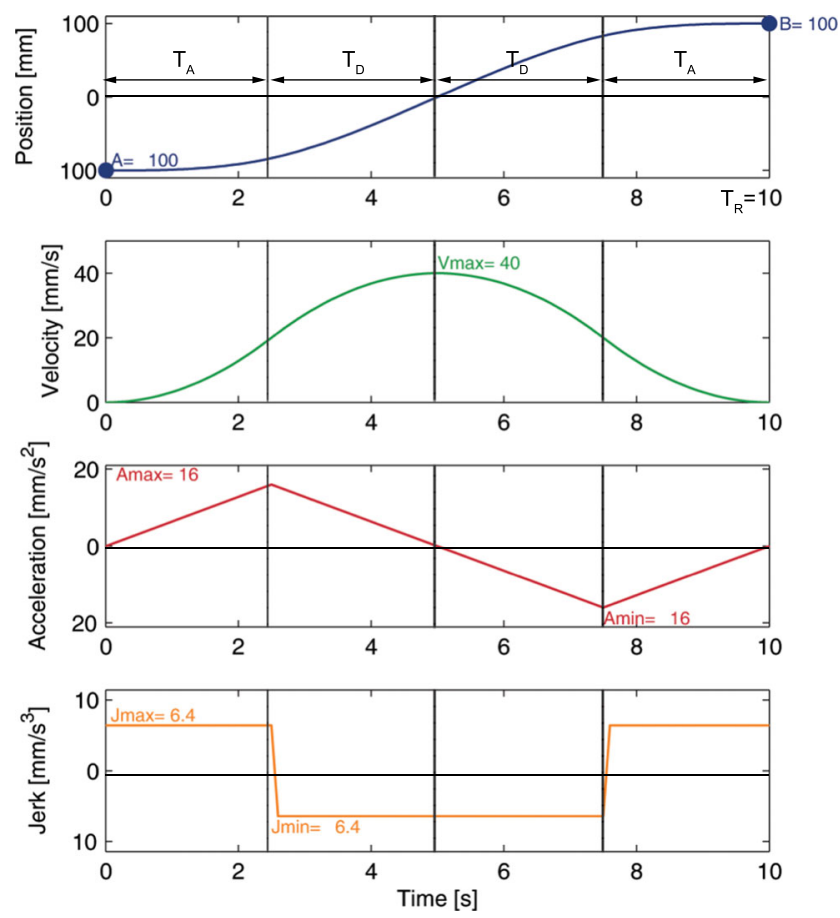

Fig. 6 Definition of a single stroke of reciprocating motion with S-curve profile 
$A=-D=\frac{v_{R \max }}{T_{A}}$

$\Delta R= \begin{cases}\frac{1}{6} J_{A} \tau_{1}^{3}, & 0<\tau_{1}<T_{A} \\ \frac{1}{6} J_{D} \tau_{2}^{3}+\frac{1}{2} A \tau_{2}^{2}+\frac{v_{\text {Rmax }}}{2} A \tau_{2}, & 0<\tau_{2}<T_{D} \\ \frac{1}{6} J_{D} \tau_{3}^{3}+v_{R \max } \tau_{3}, & 0<\tau_{3}<T_{D} \\ \frac{1}{6} J_{A} \tau_{4}^{3}+\frac{1}{2} D \tau_{4}^{2}+\frac{v_{\text {max }}}{2} A \tau_{4}, & 0<\tau_{4}<T_{A}\end{cases}$

In order to describe the constancy of the lapping wear, the trajectory-distribution uniformity is defined in Eq. 18:

$U=\left(1-\frac{S_{D}}{\bar{H}}\right) \cdot 100 \%$

where $S_{D}$ is the standard deviation of the trajectory density, and $\bar{H}$ is the average value of the trajectory distribution.

The trajectory distribution of particles in single-sided lapping process is significantly affected by $k_{1}$ and in system with additional movement of conditioning ring also by $k_{2}$. In order to obtain a better uniformity base on trajectory simulations, it is important to optimize both parameters. To determine the appropriate kinematic parameters, the maximum uniformity is set as a goal of parameters optimization.

The simulation results of the trajectory density uniformity $U$ in standard lapping system, when 1000 randomly distributed particles are considered, are shown in Fig. 7. Uniformity was calculated on the entire lapping plate with an internal diameter of $88 \mathrm{~mm}$ and an outer diameter of 350 $\mathrm{mm}$. The simulation time was $60 \mathrm{~s}$. The general results show that to obtain higher uniformity values in a standard lapping system, rotational speed ratios should equal $k_{1}=0,6-$ 0, 9 (Fig. 7a). This result coincides with the recommendations of the lapping machine manufacturers and previously conducted researches [1, 7, 12, 31]. Moreover, it can be observed that the highest uniformity $(U=58,79 \%)$ was obtained for the central position of the conditioning ring on the lapping plate. The simulation results for radial position $R_{p}=117 \mathrm{~mm}$ are shown in Fig. 7b. Moving the conditioning ring together with separators and workpieces towards the internal $R_{i n}$ or external $R_{e x}$ radius of the lapping plate decreases the uniformity $U$. A significant decrease in uniformity $(\mathrm{U}=30 \%)$ was observed when the ring was shifted towards the internal radius and the parameter $k_{1}$ is greater than 1,5 and when the ring was shifted towards the external radius and parameter $k_{1}$ is lower than -1 .

In the kinematic parameters optimization of the singlesided lapping system, with reciprocating motion of the conditioning ring, it was assumed that the ring performs a reciprocating motion from point $\mathrm{A}=(97,97)$ to point $\mathrm{B}=(97,-97)$. The maximum value of the uniformity $U$ is sought for the parameters $k_{1}$ in the range from $-2,75$ to 2,75 and $k_{2}$ in the range from 0 to 4 . The introduction of the conditioning ring motion along a chord resulted

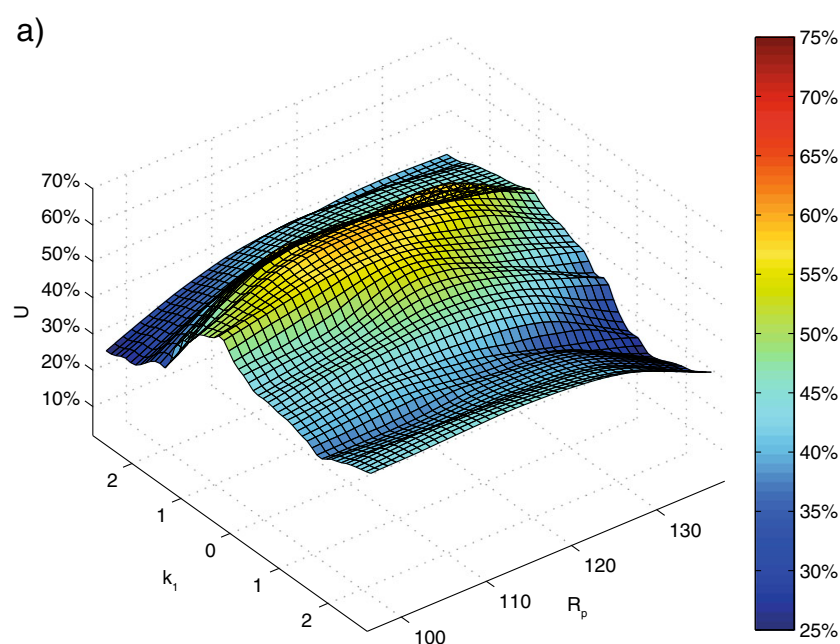

b)

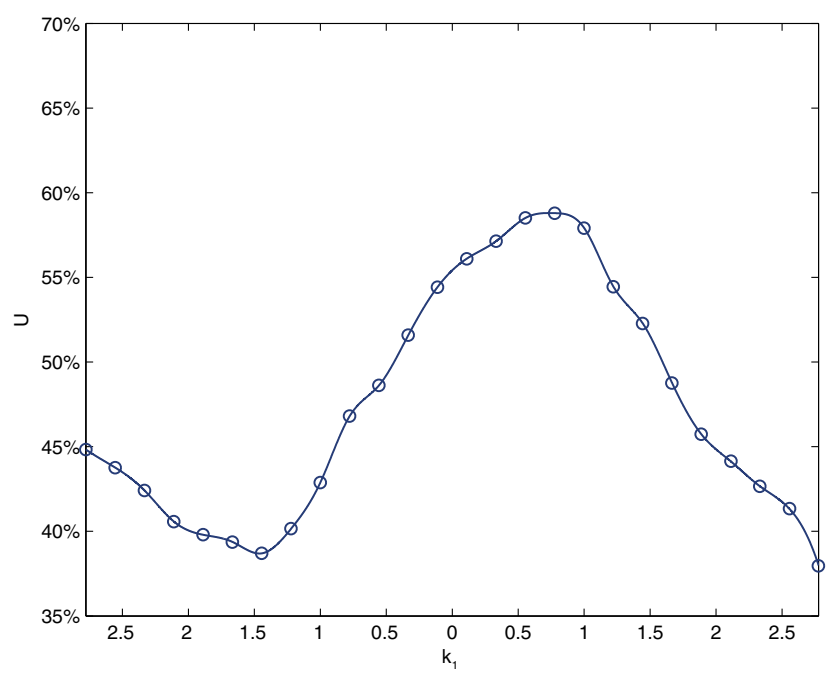

Fig. 7 Trajectory density uniformity versus speed ratio $k_{1}$ and radial position of conditioning $R_{p}$ for standard single-sided lapping system, 1000 random particles, simulation time $t=60 \mathrm{~s}$ : a general view, $\mathbf{b}$ $R_{p}=117 \mathrm{~mm}$

in increasing an average uniformity $U$ by approximately $16,8 \%$, compared to the standard lapping system. As in the standard lapping system, the most even wear of the lapping plate took place when the parameter $k_{1}$ was between 0,6 and 0,9 . In addition, the highest trajectory density uniformity $(U=69,47 \%)$ was obtained for parameters $k_{1}=0,78$ and $k_{2}=2$. The simulation results are shown in Fig. 8 .

\section{Experimental study}

\subsection{Experimental stand}

Experimental tests were performed on single-sided lapping machine Abralap 380. This lapping machine is a part of experimental stand intended for analysis of lapping plate 


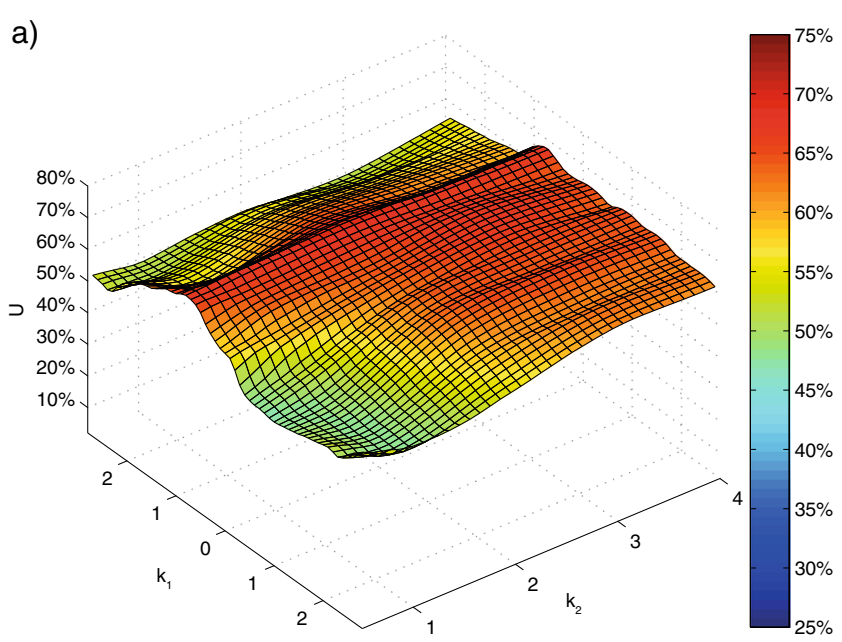

b)

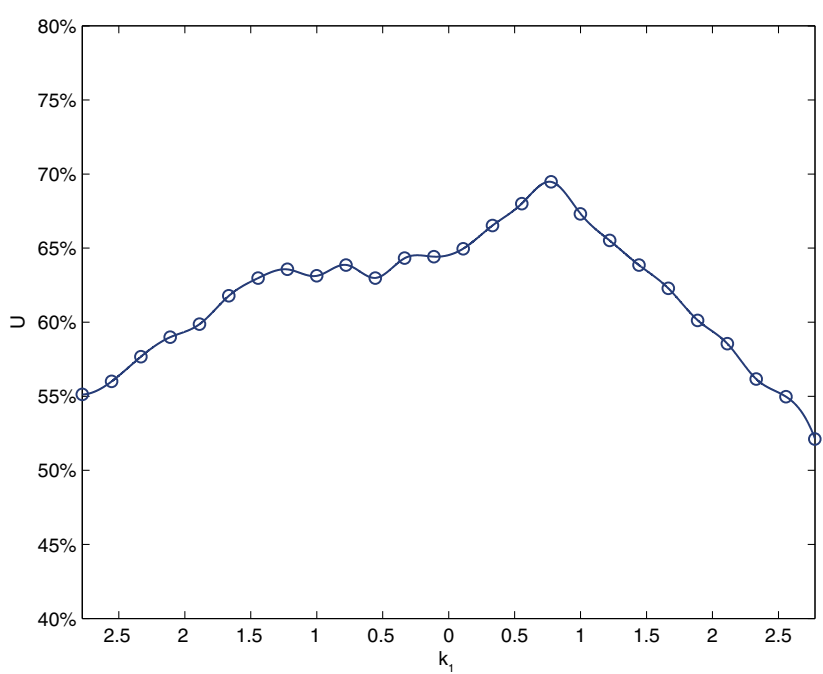

Fig. 8 Trajectory density uniformity versus speed ratios $k_{1}$ and $k_{2}$ for unconventional single-sided lapping system with reciprocating motion of the conditioning ring, 1000 random particles, simulation time $t=$ $60 \mathrm{~s}$ : a general view, $\mathbf{b} k_{2}=2$

wear in kinematic systems with additional motion of the conditional ring (Fig. 9). Above the lapping machine (1) the linear drive (2) equipped with a stepper motor (3) was fitted. Another stepper motor (4) is attached, which allows moving the conditioning ring (6) by using a special gripper (5). The system is able to control the ring's displacement and rotation speed in two directions. The stepper motors allow precise positioning and repeatable moves. The range of the linear stroke is $350 \mathrm{~mm}$. In addition, it is possible to shift the linear drive along the radius of the lapping plate. An independent measurement of the velocity of the lapping plate is taken by a revolution counter, which consists of an optical reflective sensor and a programmable tachometer. Reflecting fields were attached to the tip of the shaft, which drives the lapping plate.

What's more, the experimental stand was equipped with a measuring tool (7), which enables to take contact

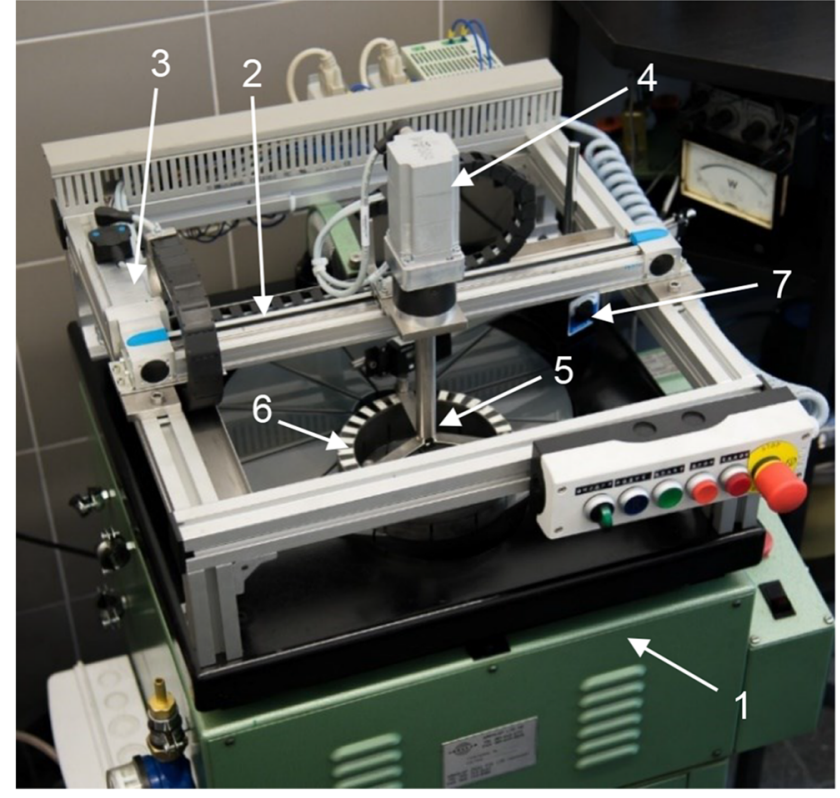

Fig. 9 Experimental stand: 1-single-sided lapping machine Abralap 380, 2-linear drive, 3-stepper motor of the linear drive, 4-stepper motor that rotates the conditioning ring, 5-gripper, 6-conditioning ring, 7-measuring tool

measurements directly on the lapping machine. The measurements allow determining the wear value of the active surface of the lapping plate after the lapping process. The tool is equipped with a digital ruler attached to the frame of the stand, which enables to move the dial gauge along the radius of the lapping plate. The digital ruler allows to read off the movement to within $0,01 \mathrm{~mm}$ and the graduation of the dial gauge is $0,001 \mathrm{~mm}$.

The main aim of experimental tests was to determine the wear profile of the lapping plate and to compare it with the profiles, which were obtained during the previously performed simulations. Less important in experimental research was the determination of the wear size. Obtained measurement results are only an approximation or estimate of the measured value; therefore, the uncertainty of the estimate was determined. The uncertainty of measurements may result from imperfect measuring system, incomplete knowledge of the environment impact on the measurements, imperfections of the observer's senses, simplifying approximations and assumptions resulting in the method and the measurement procedure. However, assuming that the main source of uncertainty is the inaccuracy of the measuring tool, the type $B$ standard uncertainty has been calculated. It takes into account the instrumental error, the resolution effect and it is $\sqrt{3}$ times lower than the limit error $\Delta x$, so it narrows the range of probable errors to approximately $58 \%$ of the limit error value of the tool. Moreover, it was assumed that there is no component correlation and 
the coverage factor $k$ equals 2 . The uncertainty $u_{B}$ of the measuring tool equals $0,0018 \mathrm{~mm}$.

\subsection{Experimental procedure and tool wear results}

Experimental studies were divided into four cycles. In each cycle, the lapping process took $90 \mathrm{~min}$ and the measurements were taken every $30 \mathrm{~min}$. During the lapping process, only one conditioning ring was used. Four tellurium copper elements with a diameter of $44,45 \mathrm{~mm}$ and loaded through a 2395-g weight disk were lapped on designed experimental stand. Into the contact region between the workpieces and the lapping tool an abrasive slurry, which consist of black silicon carbide (98C F500) $10 \%$, liquid paraffin $45 \%$, and machine oil $45 \%$, was applied. Due to the different initial lapping plate flatness of each cycle, it was decided to repeat the parameters of the cycle I after the cycle II; hence, the parameters of cycles I and III are the same. The rotational speed of the lapping plate was assumed the same for all cycles $n_{t}=$ $64 \mathrm{rpm}\left(k_{1}=0,78\right)$. Moreover, in cycles II and IV, the conditioning ring performed a reciprocating motion with the same maximum linear velocity $v_{R \max }=140 \mathrm{mmps}$ $\left(k_{2}=2\right)$, the same distance $d=194 \mathrm{~mm}$, but opposite rotational motion $\left(k_{1}=-0,78\right)$. The parameters of each cycle are shown in the Table 1.

During the first phase of study, in order to measure the flatness of the active surface of the lapping plate, Lapmaster flatness gauge was used. The tool consists of a dial gauge, which lays on three hardened feet. It is a commonly used tool to control the flatness of the plate in a fast and reliable way. First, the flatness gauge was calibrated by placing it on the master flat supplied with the gauge. The dial indicator was set as zero and then used as a reference point for measuring. The flatness was measured on 12 segments on the lapping plate. The mean of these values was a negative value at $13 \mu \mathrm{m}$, which means that the lapping plate was concave.

In the second phase, the wear of the lapping plate was measured using the measuring tool, which is the part of the test stand. Measurements were made at 5 points on the active surface of the lapping plate, spaced about $35 \mathrm{~mm}$. The results difference before machining and after machining is

Table 1 Kinematic parameters used in the subsequent cycles of the experimental studies

\begin{tabular}{lrrr}
\hline Lapping cycle & I, III & II & IV \\
\hline$n_{t}$, rpm & 64 & 64 & 64 \\
$n_{s}$, rpm & 48 & 48 & -48 \\
$R_{0}, \mathrm{~mm}$ & 117 & 97 & 97 \\
$d, \mathrm{~mm}$ & 0 & 194 & 194 \\
$v_{\text {Rmax }}$, mmps & 0 & 116 & 116 \\
\hline
\end{tabular}

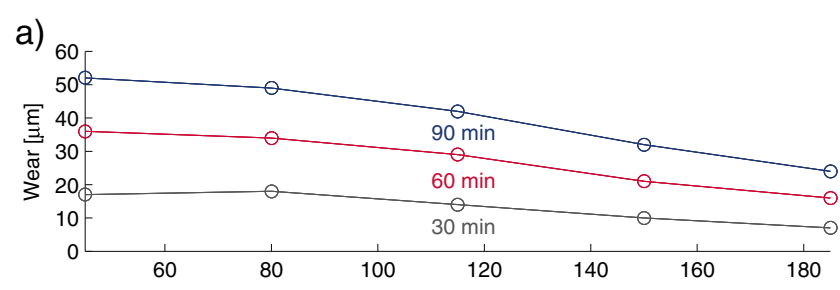

b)

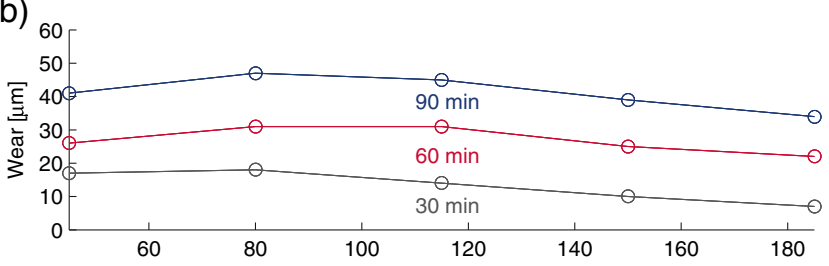

c) 60

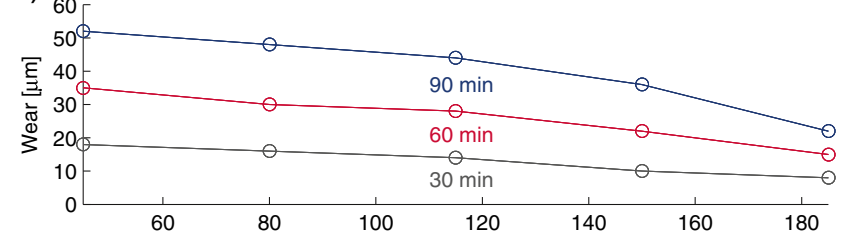

d)

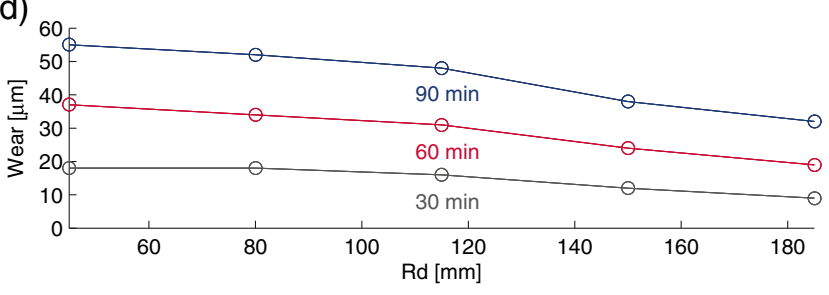

Fig. 10 Lapping plate wear after subsequent cycles of machining: a cycle I, b cycle II, c cycle III, $\mathbf{d}$ cycle IV

a size of wear. Analysis of the results (Fig. 10) shows that the wear profile overlaps to a great extent with the results obtained during the simulation of uniformity in singlesided lapping process. In order to determine a dispersion of the wear along the radius of the lapping plate, the standard deviation was calculated for each cycle, which was respectively 11,$71 ; 5,12 ; 11,87$; and $9,70 \mu \mathrm{m}$. Of all the cycles, the standard deviation was the lowest; hence, the wear profile was the most uniform in the cycle II. The lowest uniformity was obtained for the standard lapping system in cycles I and III. In addition, the results for these cycles were similar, which indicates the repeatability of the research. For cycle IV with opposite movement of the conditioning ring, a slight difference of the profile wear uniformity was observed compared to the standard system. It was noted that the introduction of additional movement of the conditioning ring increased the uniformity and the size of lapping plate wear.

\subsection{Workpieces surface finish}

Besides the grit of abrasives, the lapping parameters, especially speed ratio $k_{1}$, are the factors influencing surface 
roughness $[1,21]$. The part of the studies was to check the influence of the additional motion of the conditioning ring on the workpieces surface finish. Parameters $R_{a}$ and $R_{t}$ were measured in four places on the diameter of each workpiece. The sampling lengths $l_{r}$ equaled $0,8 \mathrm{~mm}$. The original copper surface mean roughness was $R_{a}=0,68 \mu \mathrm{m}$ and mean roughness depth was $R_{z}=10,25 \mu \mathrm{m}$. It can be seen that the surface roughness after lapping decreased (Fig. 11). The average values of the $R_{a}$ parameter for each cycle were respectively 0,$56 ; 0,51 ; 0,54$; and $0,55 \mu \mathrm{m}$ and of the $R_{z}$ parameter 4,$33 ; 3,95 ; 4,28$; and $4,20 \mu \mathrm{m}$. Based on the results, it can be found that the introduction of ring additional motion had insignificant influence on the surface roughness. However, a slight decrease in roughness can be noticed for cycle II. Generally, the roughness is related to the number of abrasive scratches on the workpiece surface, and according to the numerical results, the additional movement of the conditioning ring increases the density of the trajectories.

In addition to the roughness, the material removal of workpieces was studied in the work. The removal thickness was measured on the basis of the weight before and after the lapping, which was then mathematically converted into volume and height. Figure 12 gives the removal thickness distribution of workpieces after each lapping cycle. It can be seen that the material removal over time was almost constant and equaled 45,$5 ; 66,5 ; 44,17$; and $54,5 \mu \mathrm{m} / \mathrm{h}$ respectively. It can be seen that the material removal rate increases in the case of lapping systems with reciprocating motion of the conditiong ring, which is caused by the increase of the relative velocity. The maximum removal thickness occurred in cycle II and was about $45 \%$ higher than that in cycle I or III.
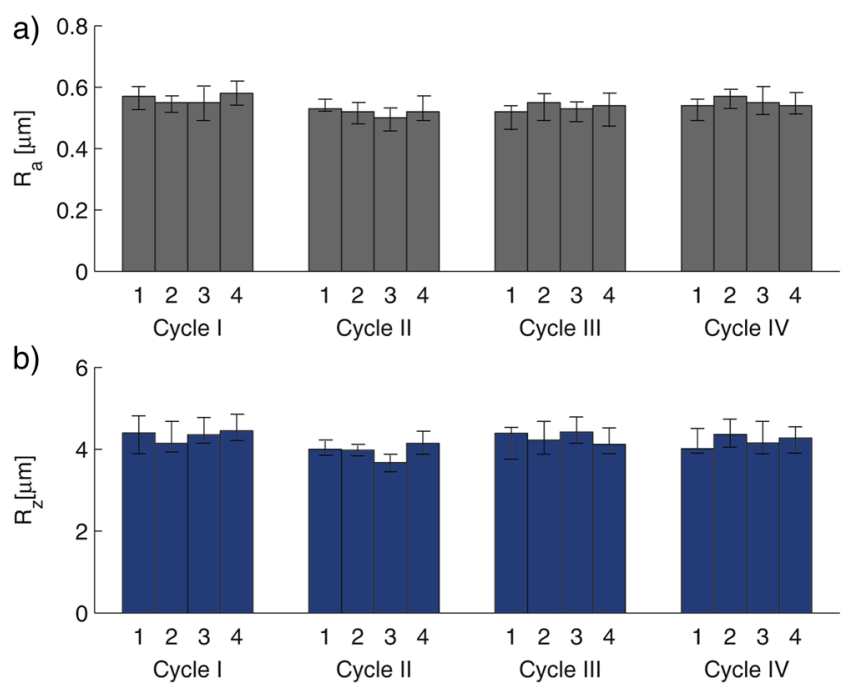

Fig. 11 Workpieces roughness after following lapping cycles: a surface mean roughness $R_{a}$, b mean roughness depth $R_{z}$

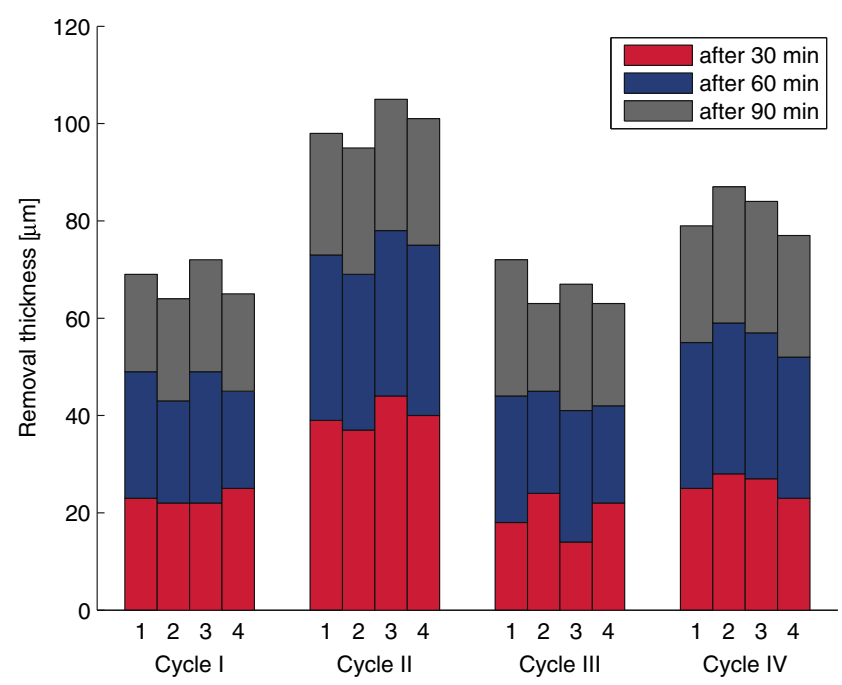

Fig. 12 Workpieces removal thickness after following lapping cycles

\section{Conclusions}

It can be established that the key to achieving good surface finish and flatness results is maintaining proper condition of a tool. The main problem that occurs in single-side lapping process is uneven wear of the lapping plate. In the paper, numerical simulations of particle sliding trajectories and their uniformity based on kinematic analysis are presented, in order to determine the optimal kinematic parameters. Furthermore, an unconventional single-sided lapping system, where a conditioning ring performs an additional motion during the machining, is described. The trajectories maps reveal that the trajectory distributions are significantly affected by the relationships among the basic motions of the lapping process. The two major factors affecting the trajectory distribution are the speed ratio $k_{1}$, which represents the rotational speed ratio of the conditioning ring to the lapping plate, and the period ratio $k_{2}$ of the reciprocating period of the conditioning ring to rotary motion period of the lapping plate. In order to optimize the kinematic parameters for better uniformity of the lapping plate wear, a material removal rate and trajectory density parameter are proposed.

It was noted that the introduction of additional movement of conditioning ring allows for a more even wear of the lapping plate. The preferred kinematic parameter values for single-sided lapping system with reciprocating motion o the conditioning ring are $k_{1}=0,78$ and $k_{2}=2$. The obtained wear uniformity was about $11 \%$ higher than in the case of a standard lapping system. Moreover, the general simulation results were validated on specially designed experimental stand. The analysis of received results shows that the wear profile overlaps to a great extent with the results obtained during the simulation of uniformity in the 
single-sided lapping process. Based on the analysis, it can be concluded that the material removal rate and surface roughness of workpieces can be also improved with speed ratios optimization.

Open Access This article is distributed under the terms of the Creative Commons Attribution 4.0 International License (http:// creativecommons.org/licenses/by/4.0/), which permits unrestricted use, distribution, and reproduction in any medium, provided you give appropriate credit to the original author(s) and the source, provide a link to the Creative Commons license, and indicate if changes were made.

Publisher's Note Springer Nature remains neutral with regard to jurisdictional claims in published maps and institutional affiliations.

\section{References}

1. Uhlmann E, Ardelt T, Spur G (1999) Influence of kinematics on the face grinding process on lapping machines. Ann CIRP 48(1):281-284

2. Deshpande LS, Raman S, Sunanta O, Agbaraji C (2008) Observations in the flat lapping of stainless steel and bronze. Wear 265(1-2):105-116

3. Belkhir N, Bouzid D, Herold V (2009) Surface behavior during abrasive grain action in the glass lapping process. Appl Surf Sci 255(18):7951-7958

4. Liu JH, Pei ZJ, Fisher GR (2007) Grinding wheels for manufacturing of silicon wafers: a literature review. Int J Mach Tools Manuf 47(1):1-13

5. Liu H-K, Chen C-CA, Chen W-C (2017) Diamond lapping of sapphire wafer with addition of graphene in slurry. Procedia Eng 184:156-162

6. Zong WJ, Li D, Cheng K, Sun T, Wang HX, Liang YC (2005) The material removal mechanism in mechanical lapping of diamond cutting tools. Int J Mach Tools Manuf 45(7-8):783-788

7. Barylski A (1992) Podstawy docierania jednotarczowego powierzchni płaskich. Zeszyty Naukowe Politechniki Gdańskiej, Mechanika 67, Gdańsk

8. Klocke F (2009) Manufacturing processes 2: grinding, honing, lapping. Springer, Berlin

9. Ardelt T (2001) Verfahrensvergleich Planschleifen mit Planetenkinematik - Planparallelläppen. IDR 35(3):214-224

10. Neauport J, Destribats J, Maunier C, Ambard C, Cormont P et al (2010) Loose abrasive slurries for optical glass lapping. J Opt A Purek Appl Opt 49:5736-5745

11. Heisel U, Jakob P (2012) Research on the workpiece kinematics in face lapping with friction drive. Adv Mater Res 565:318-323

12. Marinescu ID, Uhlmann E, Doi T (2007) Handbook of lapping and polishing. Taylor \& Francis Publishing House, New York

13. Barylski A, Deja M (2002) Calculation of flatness errors formed on the tool during finishing machining by lapping. Int J Appl Mech Eng 7:291-296

14. Ishikawa K, Ichikawa K, Suwabe H (1988) A basic study on corrective techniques to recovering accuracy of deteriorated lapping plate. Int J Jpn Soc Precis Eng (3):234-236

15. Lu LY, Fang CF, Shen JY, Lu J, Xu XP (2014) Analysis of path distribution in lapping and polishing with single fixed abrasive. Key Eng Mater 589-590:475-479

16. Ichikawa S, Ona H, Yoshimoto I, Kobayashi A (1993) Proposal of new lapping method for ceramic balls. CIRP Ann 42(1):421-424

17. Chang YP, Hashimura MM, Dornfeld DA (2000) An investigation of material removal mechanisms in lapping with grain size transition. J Manuf Sci Eng 122(3):413-419
18. Kling J, Matthias E (1986) Workpiece material removal and lapping wheel wear in plane and plane-parallel lapping. CIRP Ann 35(1):219-222

19. Spur G, Eichhorn H (1997) Kinematisches Simulationsmodell des Läppscheibenverschleißes. IDR 2:169-178

20. Simpfendorfer D (1988) Entwicklung und Verifizierung eines Prozeßmodells beim Planläppen mit Zwangsführung. Produktionstechnik - Berlin 71. Hanser-Verlag, München

21. Hu Z, Fang C, Deng W, Zhao Z, Lin Y, Xu X (2017) Speed ratio optimization for ceramic lapping with fixed diamond pellets. Int $\mathrm{J}$ Adv Manuf Technol 90(9-12):3159-3169

22. Satake U, Enomoto T, Fujii K, Hirose K (2016) Optimization method for double-sided polishing process based on kinematical analysis. Procedia CIRP 41L:870-874

23. Mahamad Sahab AR, Saad NH, Rashid AA, Noriah YF, Said NM, Zubair AF, Jaffar A (2013) Effect of double sided process parameters in lapping silicon wafer. Appl Mech Mater 393:259265

24. Fiocchi AA, Fortulan CA, Sanchez LEA (2015) Ultra-precision face grinding with constant pressure, lapping kinematics, and $\mathrm{SiC}$ grinding wheels dressed with overlap factor. Int J Adv Manuf Technol 79(9-12):1531-1543

25. Pei ZJ, Fisher GR, Bhagavat M, Kassir S (2005) A grindingbased manufacturing method for silicon wafers: an experimental investigation. Int J Mach Tools Manuf 45(10):1140-1151

26. Qin N, Guo DM, Kang RK, Huo FW (2009) Effect of conditioning parameters on surface non-uniformity of polishing pad in chemical mechanical planarization. Key Eng Mater 389-390(1):498-503

27. Li ZC, Baisie EA, Zhang XH (2012) Diamond disc pad conditioning in chemical mechanical planarization (CMP): a surface element method to predict pad surface shape. Precis Eng 36(2):356-363

28. Hocheng H, Tsai HY, Tsai MS (2000) Effects of kinematic variables on nonuniformity in chemical mechanical planarization. Int J Mach Tools Manuf 40(11):1651-1669

29. Lee H, Lee S (2017) Investigation of pad wear in CMP with swingarm conditioning and uniformity of material removal. Precis Eng 49:85-91

30. Nguyen NY, Zhong ZW, Tian Y (2015) An analytical investigation of pad wear caused by the conditioner in fixed abrasive chemical-mechanical polishing. Int J Adv Manuf Technol 77(58):897-905

31. Barylski A, Piotrowski N (2014) Koncepcje niekonwencjonalnych układów kinematycznych docierania jednotarczowego z wykorzystaniem robota. Mechanik 78(8-9):36-33

32. Barylski A, Piotrowski N (2016) Multi-criteria robot selection problem for an automated single-sided lapping system. Mechatronics: Ideas, Challenges, Solutions and Applications Advances in Intelligent Systems and Computing 414:1-13

33. Evans J, Paul E, Dornfeld D, Lucca D, Byrne G, Tricard M, Klocke F, Dambon O, Mullany B (2003) Material removal mechanisms in lapping and polishing. STC "G"? Keynote. CIRP Ann 52(2):611-633

34. Tseng WT (1999) Comparative study on the roles of velocity in the material removal rate during chemical mechanical polishing. J Electrochem Soc 146(5):1952-1959

35. Wen D, Qi H, Ma L, Lu C, Li G (2016) Kinematics and trajectory analysis of the fixed abrasive lapping process in machining of interdigitated micro-channels on bipolar plates. Precis Eng 44:192-202

36. Zhao D, Wang T, He Y, Lu X (2013) Kinematic optimization for chemical mechanical polishing based on statistical analysis of particle trajectories. IEEE Trans Semicond Manuf 26(4):556-563

37. Li X (2010) Optimize S-Curve Velocity for Motion Control. Far East Journal of Applied Mathematics (48): 1-15

38. Nguyen KD, Ng T-C, Chen I-M (2008) On algorithms for planning S-curve motion profiles. Int J Adv Robot Syst 5(1):99-106 